\title{
STUDIES ON SOME PARASITIC FAUNA OF CATTLE EGRET (BUBULCUS IBIS) IN KAFR EL-SHEIKH GOVERNORATE
}

\author{
Harfoush. M.A, I.S. EL-Shahawy and A.Y. Metwally
}

Animal Health Research Institute (Kafr El-Sheikh regional Lab.)

\begin{abstract}
The present study was carried out to determine the prevalence and description of parasites infecting cattle egret(B. ibis)in Kafr El-Sheikh governorate.The obtained results showed that the overall prevalence of the parasiticfauna among cattle egret was $87.3 \%$ and the most prevalent species was Nematodes followed by Digenetic trematodes and finally the ectoparasitic one(lice) with their infection rates of $74.64 \%, 67.60 \%$ and $42.25 \%$, respectively. Also seven species of parasites (3 species of digenetic trematodes, 3 species of nematodes and one species of lice) were recovered from this study. The recorded digenetic trematodes was Apharyngostrigea ibis (35.2\%), Nephrostomum ramosum (18.3\%) and Apatemon gracilis(14.1\%), while the recovered nematodes were Synhimantus invaginatus (53.5\%), Porrocaecum wui (12.7\%) and Heterocheilus sp.(8.5\%). The latter species was recorded for the first time in cattle egret, while the detected ectoparasitic one was Menacanthus stramineus. The morphological description of the detected parasites was completely studied and discussed.
\end{abstract}

\section{INTRODUCTION}

Free living birds especially the wild ones are known to live everywhere and they play an important role in the process of biological control of the most agricultural and domestic life enemies as rodents, reptiles, amphibian, mollusca, earthworms and arthropods. In addition to their major roles in the transmission of many dangerous parasitic diseases to other domesticated birds, mammals and man either by direct or indirect means, there are many records of human infection with trematodes which are parasites of birds (Watson, 1960). 
Cattle egret (Bubulcus ibis), as one of the feral birds is commonly found in Egypt. It had adopted the habit of feeding at road sides, verged and even on the urban lawns, and will roost readily in both country and urban surroundings. It is taken as a farmer friend since it eagerly follows ploughing and feeds on harmful worms and insects.

Cattle egret like other birds suffering from various parasitic diseases as mentioned previously by many authors as Ukoli (1967); Whittaker et. al. (1971); Stuart et. al. (1972); Fischthal and Whittaker (1977); Hegazi (1978); Rajvanshi and Gupta (1983); El-Sheikh and Hegazi (1984); Ahmed (1994); Yaochi et. al. (2000) and Desoukey (2003).

Due to wide range of wild birds and the little information about the parasitic fauna of the cattle egret in our locality so, the aim of the present study is to make a spot light on the parasitic fauna of the cattle egret ( $B$. ibis)regarding to their Prevalence,Morphology as well as the Pathological lesions.

\section{MATERIAL AND METHODS}

\section{I- Birds}

A total number of 71 Cattle egret (B. ibis)were collected by hunting from some localities in Kafr El-Sheikh Governorate(Faculty of Agriculture, Mehalet El-Kasb village and El-Hamraa village)during a period extending from June 2003 to January 2004.

The collected birds were transported to the laboratory for parasitological examinations.

\section{II- Parasitological examination}

\section{II- 1- Ectoparasites}

The feathers and unfeathered parts of each bird were examined thoroughly by naked eye and by the aid of the hand lens and bright light for any Ectoparasites. 
The positive samples were collected either by brushing of the updown birds or by extraction of the parasites from the feathers, then the external parasites were received in clean Petri dishes containing water.

The collected parasites were placed in $70 \%$ alcohol containing 5\% glycerin, then cleared in Lactophenol, mounted in glycerin gelatin and then identified according to Manuel (1981).

\section{II-2-Helminthes:}

The alimentary tract (crop, proventriculus, gizzard and intestine) of each bird was examined for the presence of any enteric parasites either macroscopically by naked eye or microscopically via examination of the tract scraping.

The collected trematodes were washed several times with physiological saline,then pressed,fixed,stained,dehydrated and mounted in Canada balsam according to the technique described by Kruse and Pritchard (1982), while nematodes had been killed and stretched in a hot solution of $70 \%$ alcohol containing $5 \%$ glycerin, then cleared in lactophenol solution and mounted in glycerin gelatin according to the technique described by Belding (1965) \& Abd El-Rhaman et. al. (1982).

The collected helminthes were identified according to Yamaguti (1958).

\section{RESULTS}

\section{I- Prevalence of the detected parasites:}

The obtained results showed that the over all prevalence of the parasitic infestation among cattle egret was $87.3 \%$. Also the present results found that the total prevalence of the detected ectoparasites (lice), digenetic trematodes and nematodes was $42.25 \%, 67.60 \%$ and $74.64 \%$ respectively. Seven species of parasites (3 species of digenetic trematodes, 3 species of nematodes and one species of lice) were recorded from this 
study. The detected ectoparasitic one was Menacanthus stramineus and The recorded digenetic trematodes were Apharyngostrigea ibis, Nephrostomum ramosum and Apatemon gracilis with their infection rates of $35.2 \%, 18.3 \%$ and $14.1 \%$ respectively, while the recovered nematodes were Synhimantus invaginatus, Porrocaecum wui and Heterocheilus $s p$. with their infection rates of $53.5 \%, 12.7 \%$ and $8.5 \%$ respectively. The Heterocheilus $\boldsymbol{s} \boldsymbol{p}$. was recorded for the first time in cattle egret in Egypt. On other hand the detected lice species was identified as Menacanthus stramineus.

From the fore-mentioned results, it is concluded that the most prevalent parasitic fauna of cattle egret was nematodes followed by trematodes and finally the ectoparasitic ones. Concerning species, the most prevalent nematodes species was Synhimantus invaginatus, while for trematodes was Apharyngostrigea ibis.

\section{II- Morphology of the detected parasites:}

\section{1- Lice}

\section{Menacanthus stramineus (Nitzsch, 1818) Fig. (1)}

Site: less feathered parts of the body as shaft of the wings, breast.

Small in size, measuring 2-3mm. The head is much larger occupying the width of the body. The legs have two claws and Characterized by their abdominal segment have two dorsal rows of bristles.

\section{2- Digenetic trematodes}

2- a-Apharyngostrigea ibis (Azim, 1935) Fig. (2)

Site: intestine

The fluke measures $2.8-4.5 \mathrm{~mm}$ in length. Its body divided into pear shaped fore body and cylindrical hind body. The oral sucker is rounded in shape. The pharynx is absent. The tribocytic organ is divided by a $\overline{\text { Kafr El-Sheikh Vet. Med. J. Vol. } 2 \text { No. } 1 \text { (2004) }}$ 
vertical cleft into 2 halves. The hind body is larger than the fore ones and contains the genital organs. The testes are lobulated in shape and tandem in position. The ovary is small, ovoid in shape. The vitelline gland fills the lateral field of the body from the posterior of the tribocytic organ to the posterior end of the hind body. The eggs are oval in shape, measuring $0.09-0.1 \mathrm{~mm}$.

\section{2-b- Nephrostomum ramosum (Sonsino, 1895) Fig. (3)}

Site: intestine

The fluke is elongated in shape, measuring 11-17 x 1.4-2.6mm. The head collar is reniform and carries a single dorsally uninterrupted row of strong spines (46-50). The oral sucker is rounded in shape while the ventral one is funnel in shape and lies at the fourth quarter of the body. The pharynx is absent while the esophagus is short and bifurcated anterior to the ventral sucker into 2 simple intestinal caeca which terminate near the posterior end of the body. The testes are elongated and tandem in position. The ovary is rounded in shape and lies anterior to the testes. The vitelline glands occupy the entire lateral field from level of the ventral sucker to the posterior end of the body. The eggs are oval in shape,operculated and measures $0.09-0.11 \mathrm{~mm}$.

\section{2-c-Apatemon gracilis (Szidat, 1928) Fig. (4)}

Site: intestine

The fluke measures $2.2-4.3 \mathrm{~mm}$ in length. Its body divided into cupshaped fore body and cylindrical or saccular hind body. The tribocytic organ is divided by a vertical cleft into 2 halves. The hind body is more or less arched without neck portion. No pseudosucker. The vitelline gland is confined to the hind body. The bursa is terminal without muscular ring. 


\section{3- Nematodes:}

\section{3-a- Synhimantus invaginatus (Linstow, 1901) Fig. (5)}

\section{Site: Gizzard}

It is medium sized, white colored nematodes with cylindrical body tapering at both ends. The cuticle is thin and transversely striated. The cordons are recurrent and anastomosing. The lips are conical in shape and the buccal capsule is funnel in shape at the base of the lips. The esophagus is cylindrical in shape and the tricuspid cervical papillae and the excretory pore posterior to the cordons. Male worm is shorter than female one, measuring 7.6-12.1 length $x$ 0.21-0.35mm width. Its caudal alae are supported by 4 pairs of pre-cloacal and 5pairs of post-cloacal pedunculated papillae. The spicules are subequall and dissimilar. Female measures 12-15 long x 0.43-0.6 mm. wide, its vagina is surrounded by the prominent muscle fibers and the vulva is immediately anterior to the anus on a central prominence which is the real posterior extremity of the body as a small conical tail. The eggs are oval in shape, measuring $0.029 x$ $0.012 \mathrm{~mm}$.

\section{3-b- Porrocaecum wui (Hsu, 1933) Fig. (6)}

Site: intestine

The worm is large in size, measuring $10-12 \mathrm{~cm}$ long $\mathrm{x} 0.7 \mathrm{~mm}$ width. The cuticle is transversely striated. The mouth is surrounded by large 3lips; the dorsal lip has a distinct median cleft at its anterior extremity, while the two lateral ones have rounded borders. The anterior part of esophagus is long while the posterior part is oblong. The female vulva is flushed with body and present near to the middle of the body, while the male spicules are equal. The eggs are rounded in shape.

\section{3-c- Heterocheilus sp.(Diesing,1839) Fig. (7)}

It is medium sized, brownish in color nematodes, measuring $2-3 \mathrm{~cm}$ long and $0.5 \mathrm{~mm}$ wide. The mouth is surrounded by 3 prominent complex lips. The esophagus is cylindrical, slightly enlarged posteriorly. Male is 
shorter than female, its tail almost straight,conical and sharp pointed. The spicules are long, equal and alate. It has 3pairs of preanal and 5pairs of postanal papillae, while the female tail is tapering and its vulva present near the anus.

\section{DISCUSSION}

The obtained results concluded that the overall prevalence of parasitic infestation among cattle egret was $87.3 \%$. This high prevalence might be attributed to the fact that the wild birds have usually fed a diet containing a high proportion of arthropods, earthworm, mollusca, fish, reptiles and rodents, many of them are intermediate hosts for helminthes, means that these birds carry a high parasitic burden.

The present study revealed that the total prevalence of digenetic trematodes and nematodes was $67.60 \%$ and $74.64 \%$ respectively and the detected digenetic trematodes were Apharyngostrigea ibis, Nephrostomum ramosum and Apatemon gracilis with their infection rates of $35.2 \%, 18.3 \%$ and $14.1 \%$ respectively. These results were similar to those obtained by Azim (1934\&1935) who found that Nephrostomum ramosum and Apharyngostrigea ibis recovered from Ardeola ibis ibis in Egypt,Bisseru(1957) reported Apharyngostrigea ibis from the intestine of buff backed heron; Fischthal and Whittaker (1977)who recovered Nephrostomum ramosum from the intestine of cattle egret; El-Naffar and Khalifa(1975) recovered Apharyngostrigea ibis, Nephrostomum ramosum and Apatemon gracilis from cattle egret.

Concerning the prevalence of the above mentioned trematodes, the obtained results were nearly similar to that recorded by Hegazi (1978) and El-Sheikh and Hegazi (1984) who reported that the prevalence of trematodes among Ardeola ibis ibis was 50\%. Apharyngostrigea ibis, the present results disagreed with those obtained by Ukoli (1967), Hegazi (1978), El-Sheikh and Hegazi (1984) and Ahmed (1994) who recorded a 
high prevalence of this species as $85 \%$ in Ghana, $47.05 \%$ in Egypt and $61.9 \%$ respectively, while for Nephrostomum ramosum the obtained results were nearly similar to that recorded by Rajvanshi and Gupta (1983) who reported the prevalence of Nephrostomum ramosum was $22.9 \%$ and disagreed with those of Stuart et.al.(1972),El-Sheikh and Hegazi (1984) and Ahmed (1994) who recorded a high prevalence of this species $40 \%$, $82.3 \%$ and $38.09 \%$ respectively. This variation might be attributed to the difference in the climatic condition and nature of pasture.

While the recovered nematodes were Synhimantus invaginatus, Porrocaecum wui and Heterocheilus sp.with their infection rates of 53.5\%, $12.7 \%$ and $8.5 \%$ respectively. These results were nearly similar to that reported by Kumar and Gupta (1979); Wong and Anderson (1986) and Conti et.al.(1986)where they recorded the same species from the gizzards of the cattle egret.Synhimantus invaginatus, the present results were nearly similar to that obtained by Stuart et. al. (1972) who mentioned the prevalence of this species was $47 \%$ and disagreed with that of Whittaker et. al. (1971)who stated that its prevalence was $5 \%$ in cattle egret.Porrocaecum wui the present results disagreed with that obtained by Ahmed (1994) who recorded the prevalence of it was $4.7 \%$.Heterocheilus $s p$. This species was recorded for the first time in cattle egret in Egypt and this result agreed with that of Yaochi et.al.(2000) who recovered this worm from Ardeidae birds in Taiwan.

Regarding to the morphological description of the detected parasites, the results in this work was similar to those mentioned before by many authors as Ali (1968); El-Naffar and Khalifa (1975); Hegazi (1978); Kumar and Gupta (1979); Ahmed (1994); Yaochi et. al. (2000) and Desoukey (2003). 


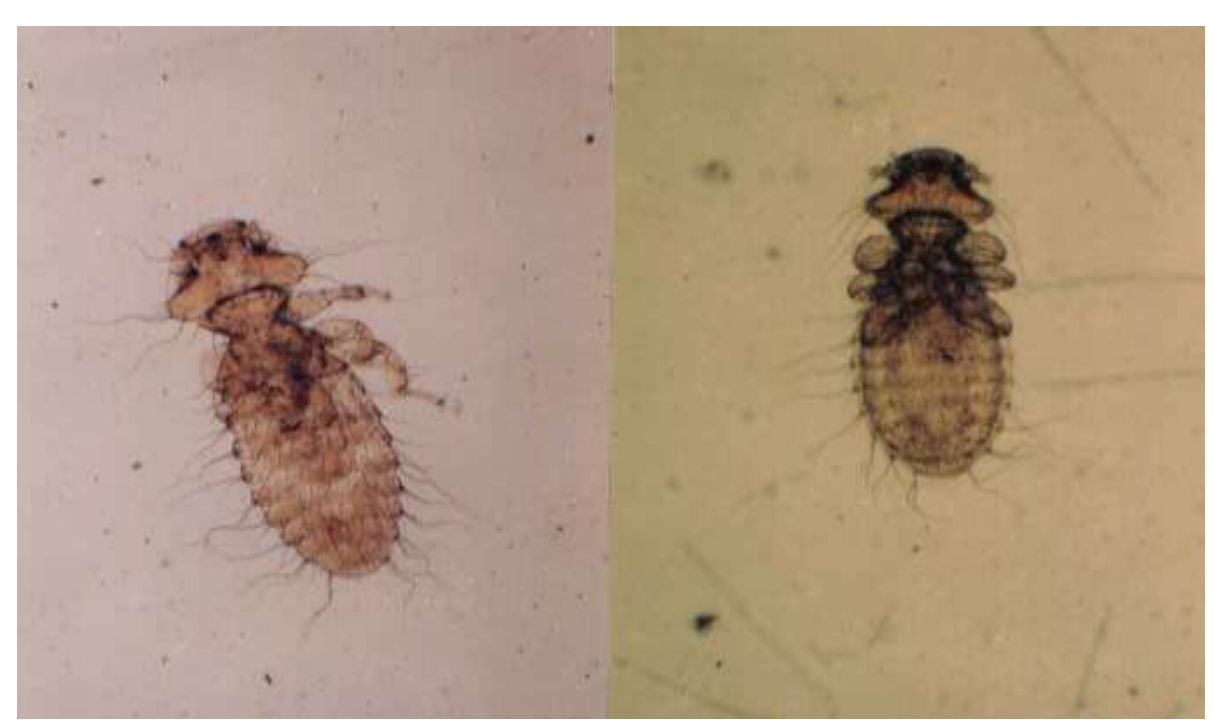

Fig. (1): Menacanthus stramineus (X 16 x 12.5)

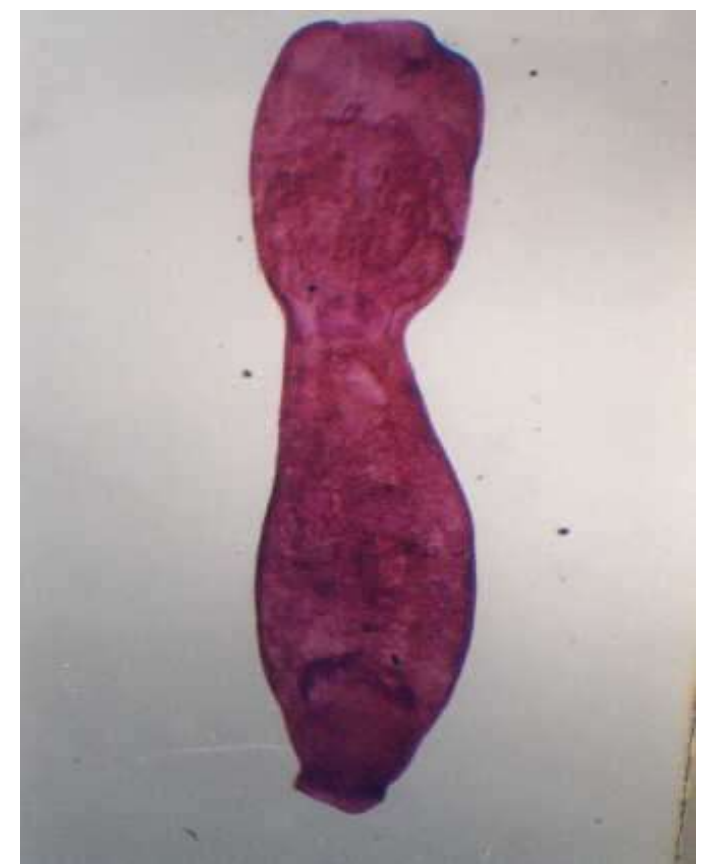

Fig. (2): Apharyngostrigea ibis (X 16 x12.5) 
M.A. Harfoush., et.al.

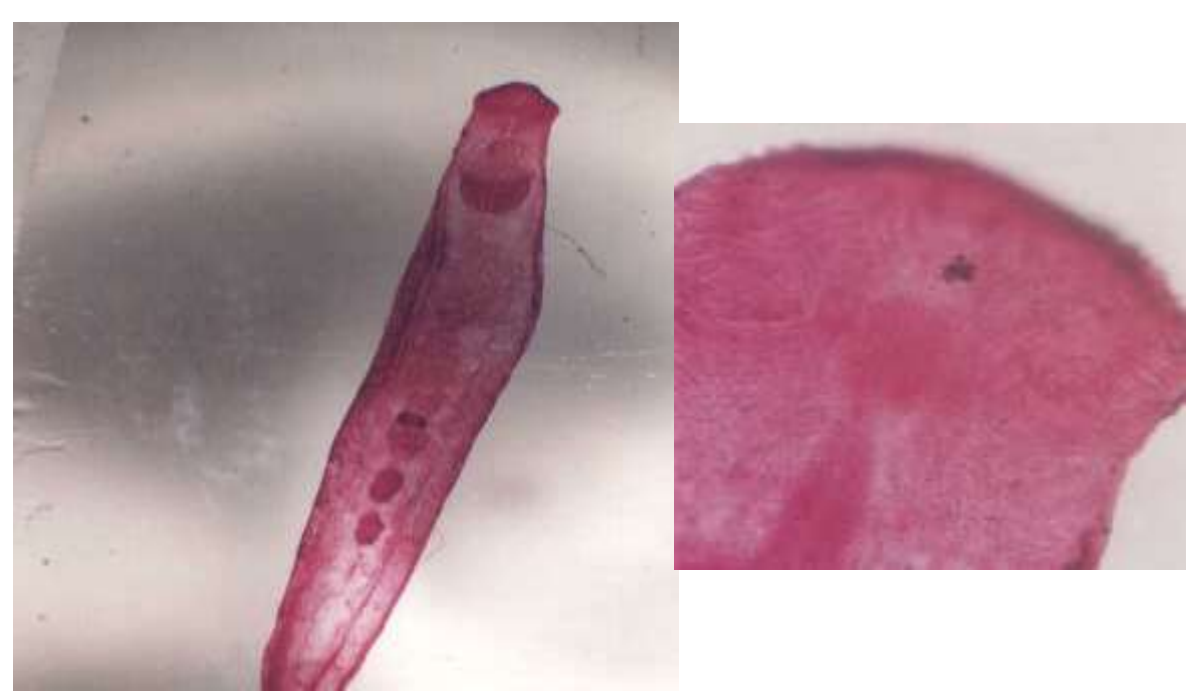

Fig. (3): Nephrostomum ramosum (X 16 x12.5)

(B) Head (40x12.5)

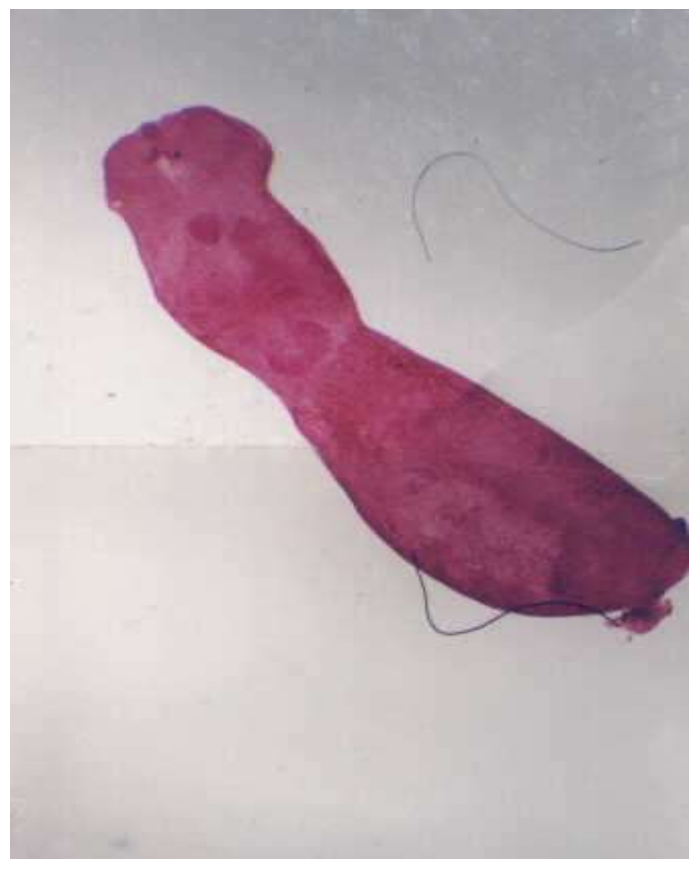

Fig. (4): Apatemon gracilis (X 16 x12.5) 


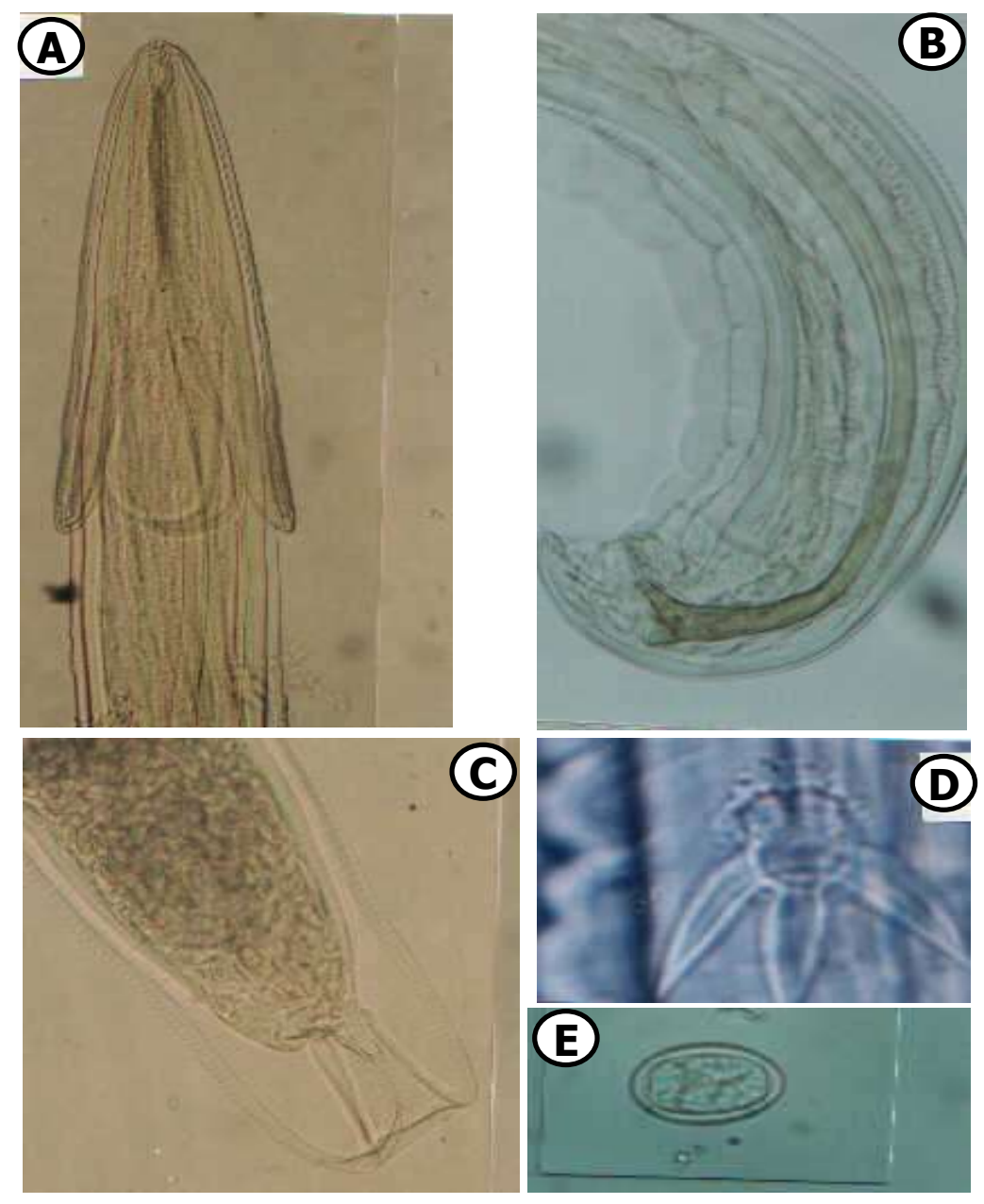

Fig. (5): Synhimantus invaginatus
(A) Anteroir end (X 10x12.5)
(B) Male posterior end (X 10x 12.5)
(C) Female posterior end (X 10x12.5)
(D) Cervical papillae (40x12.5)
(E) Eggs (X 10x12.5) 

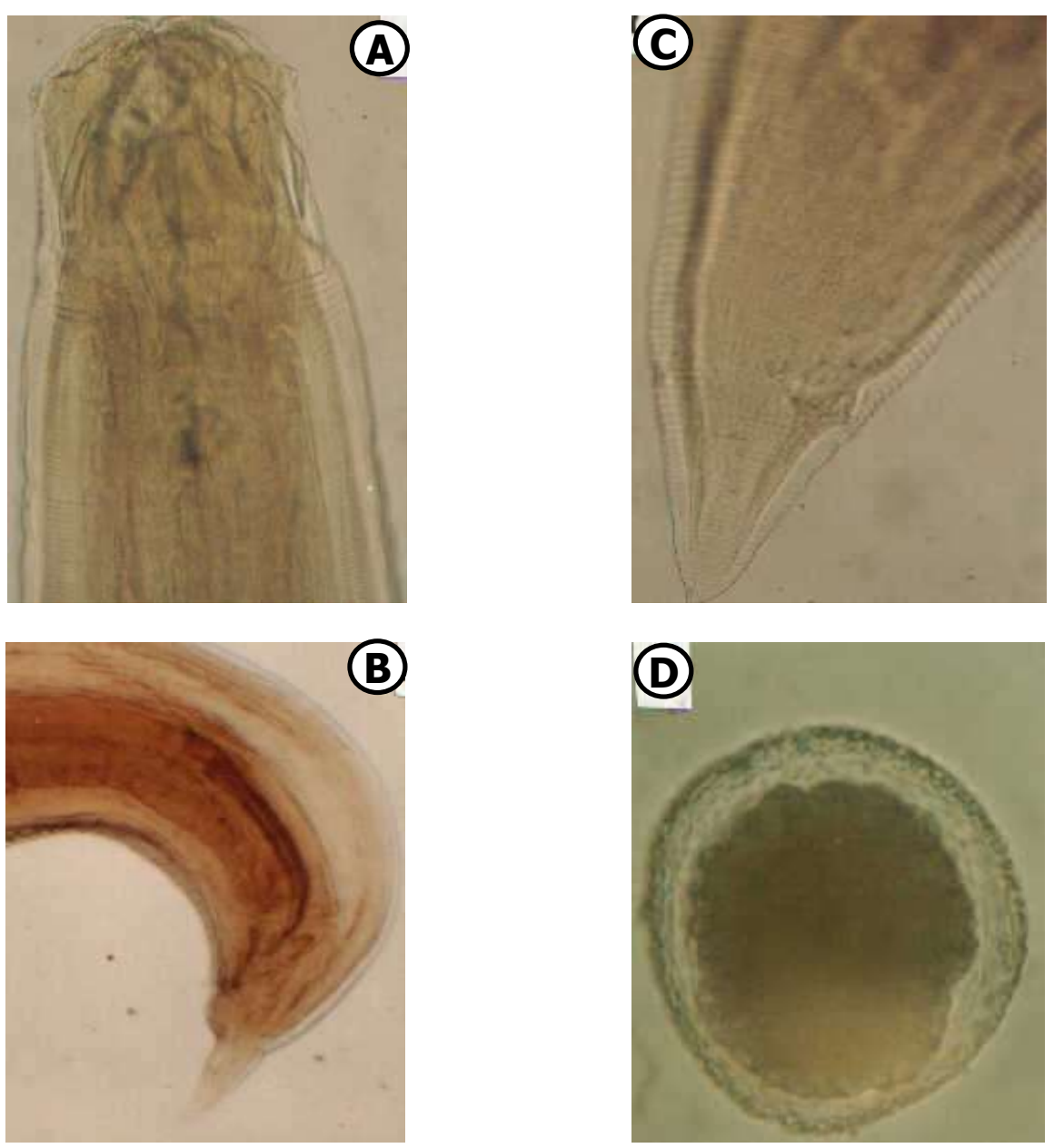

Fig. (6): Porrocaecum wui
(A) Anteroir end (X 10x 12.5)
(B) Male posterior end (X 10x12.5)
(C) Female posterior end (X 10x12.5)
(D) Eggs (40x 12.5) 


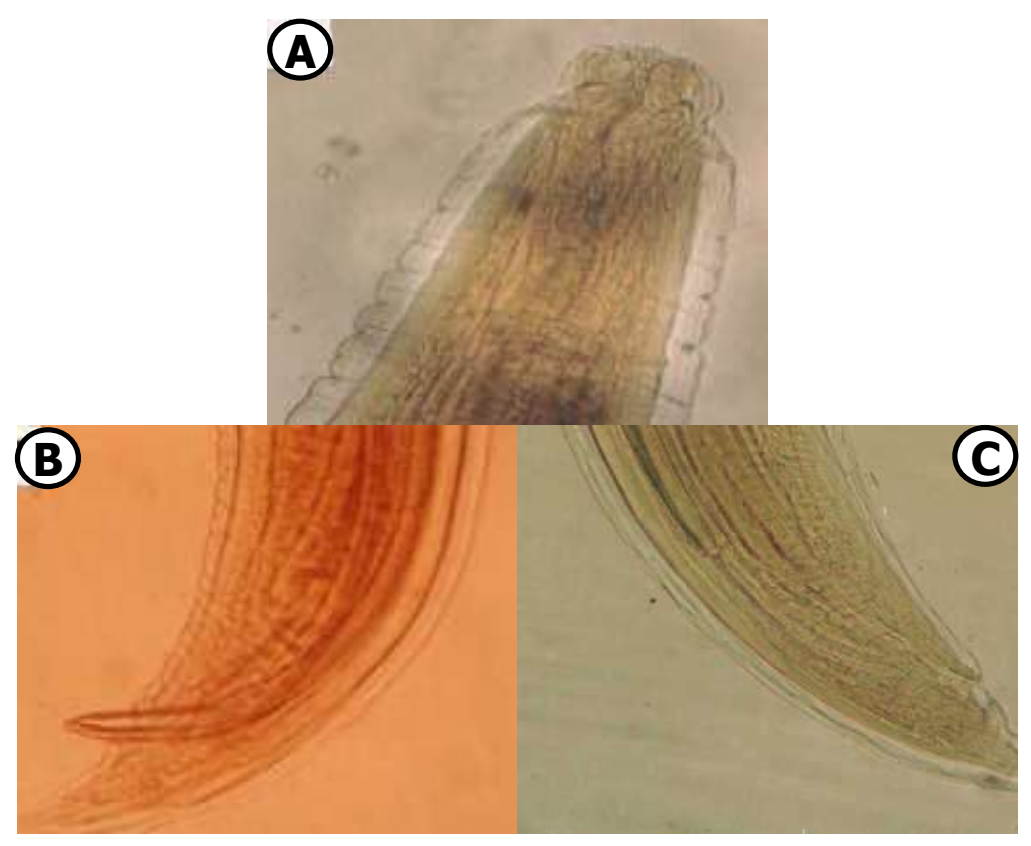

Fig. (7): Heterocheilus sp.
(A) Anteroir end (X 10x 12.5)
(B) Male posterior end (X 10x12.5)
(C) Female posterior end (X 10x12.5)

\section{REFERENCES}

- Abdel-Rahman, M.S.; Hilali, M. and Selim, M.K. (1982):Diagnostic techniques of parasites of Vet. Med. (Ed.)Fac. Vet. Med. Cairo Univ.

- Ahmed, N.M. (1994): Helminth parasites of some wild birds. M.V.Sc. Thesis, Fac. Vet. Med., Zagazig Univ.

- Ali, M.M.(1968): Studies on Spiruroid parasites of Indian birds part II. Anew genus and five new species of Acuarriidae, 
together with a key to the genus Echinuria. J.Helminth., XLII(3/4),221-242.

- Azim, M.A. (1934): On the life history of Nephrostomum ramosum Sonsino, 1895 and Echinostome parasite from Ardeola ibis ibis.Annals and magazine of natural history Ser., 10(14), 154- 157.

- Azim, M.A. (1935): Entwicklung geosohichts von Apharyngostrigea ibis n.sp.in dem.Reiher Ardeola ibis ibis. Z.Parasitkde.,7 Heft,608-614.

- Belding,D.A.(1965)Textbook of parasitology $3^{\text {rd }}$ ed.AppletonCentury - Croft., Medredith publishing company, New York.

- Bisseru, B. (1957): Two new species of trematodes (Protodiplostoma-tidae) from an African Crocodile and a list of strigied parasites from Africa. J. Helminth., XXXI (1/2), 85102.

- Conti,J.A.;Forrester,D.J.and Paul,R.T.(1986): Parasites and diseases of Reddish egrets (Egretta rufescens)from Texas and Florida. Trans. Amer. Micr. Soc., 105(1), 79-82.

- Desoukey,A.Y. (2003): Studies on digenetic trematodes infesting some Egyptian wild birds. Egypt. Vet. Med. Soc. Paras. J., 1(1), 87-108.

- El-Naffar, M.K. and Khalifa, R.M. (1975) Parasitofauna of Egyption aquatic birds 1- Trematode parasites of the buff backed heron (Ardeola ibis ibis) in Assuit Gov. J. Egypt. Soc. Parasit., (4\&5), 42-56.

- El-Sheikh, H.E. and Hegazi, A.M.(1984) Studies on the Helminth parasites of some Egyptian wild birds. Bull.Fac. Sci. Zagazig Univ., 6, 560-574. 
- Fischthal, J.H. and Whittaker, F.H.(1977) Two digenetic Trematode from the cattle egret,Bubulcus ibis from PuertoRico.J.Parasit.,63,491.

- Hegazi,M.A.(1978): Studies on some invertebrate parasites in Egyptian birds. M.V.Sc. Thesis, Fac. Sc., Tanta Univ.

- Kruse, G.O. and Pritchard, M.H. (1982): The collection and preserv-ation of animal parasites. Nebraska press, U.S.A.

- Kumar, P. and Gupta,S.P. (1979): On two species of genus Synhim-antus Railliet,Henry and Sissoff 1912(Family: Acuariidae Seurat,1913) from avian host from Lucknow. Rivista di Parasit., 40 (1/2), 81-86.

- Manuel, M.F. (1981): The ectoparasites(lice and mites)occurring on domestic chicken in Philippines. Philip. J. Vet. Med., 20(1), 87-117.

- Rajvanshi, I. and Gupta, A.N.(1983): Qualitative and quantative analysis of digenetic trematodes fauna in cattle egret, Bubulcus ibis. Proc. Ind. Acad. Parasit., 4(1/2), 1-5.

- Stuart, J.V; Dimukes, J.F. and Dix, C.F. (1972): Endoparasites of the cattle egret, Bubulcus ibis in Alabama. J. Parasit., 58(3), 1518.

- Ukoli, F.M. (1967): On Apharyngostrigea Apharyngostrigea simplex (Johnston,1904) new Comb. And Apharyngostrigea Apharyngostrigea Serpentia n.sp. (Strigeidae: trematoda) with an evaluation of taxonomy of the genus Apharyngostrigea Ciurea, 1927 by method of numerical taxonomy. J. Helminth., XLI(2/3), 235-256.

- Watson,T.M.(1960): Medical Helminthology.Bailliere Tindal and Cox, London. 
- Whittaker, H.; Schmidt, D. and Diaz, J.G.(1971): Helminth parasites of the cattle egret in Puerto- Rico. Proc. Helminth. Soc. Wash.,38,262.

- Wong,P. and Anderson, R. (1986): Revision of genus Desportesius Chabaud and Compana,1949(Nematoda: Acuaroidea) mainly from the gizzard of Ciconiiform birds. Cand. J. Zool., 64, 2520-2530.

- Yamaguti, S. (1958): Systema Helminthum. Vol. 1\&2 the digenetic trematodes and nematodes of vertebrates. Interscience publishers Inc., New York and London.

- Yaochi, S.; Changyoung, F.;Yu, S. and Cya, F.(2000): Endoparasitic helminthes of Ardeidae birds in Taiwan. AsiaSeasonally- report of environmental microbiology, 9(1), 11-18.

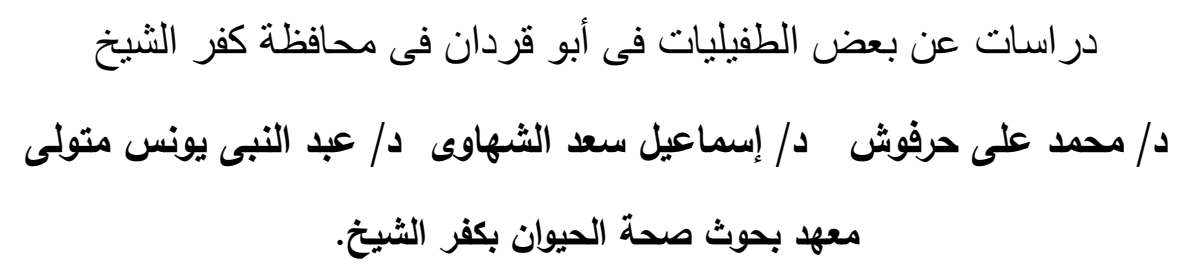

أجريت هذه الدراسة لإلقاء بعض الضوء علي بعض الطفيليات التي تصيب أبو قردان في محافظة كفر الثيخ. أوضحت الدراسة أن نسبة الإصابة العامة بالطفيليات كانت 3 و87\%. كما أوضحت الدراسة أيضا أن نسبة الإصابة بالديدان الأسطوانية 64 و74\%، بينما نسبة الإصابة بالديدان ثنائية العائل 6 و67\% وكانت نسبة الإصابة بالطفيليات الخارجية 25و 42\%. سبعة أنواع من الطفيليات تم تسجيلها من خلال هذه الدراسة منها 3 أنواع من الديدان الأسطوانية، 3أنواع من الديدان ثنائية العائل ونوع واحد من القمل. تم دراسة هذه الطفيليات مورفولوجيا. 
